\title{
Cambio e Historia: necesidades y posibilidades del análisis historiográfico a través de las «experiencias de transformación»
}

Pablo Ortega-del-Cerro

Universidad de Murcia

pablo.ortega1@um.es

Fecha recepción 03.01.2018 / Fecha aceptación 17.02.2018

\section{Resumen}

El presente trabajo tiene por objetivo hacer una revisión de algunos problemas metodológicos del análisis historiográfico del cambio social. Se pretende superar la idea esencial de que las transformaciones sociales adoptan formas de transiciones entre modelos de sociedad, se quiere subrayar la complejidad de las mutaciones y se intenta reclamar un examen de los cambios a través de una

\begin{abstract}
The main objective of this present paper is to review some methodological problems of the historical analysis of social change; the aim is to overcome the idea that postulates that social transformations adopt forms of transitions between models of society. This works seeks to emphasize the complexity of mutations and try to claim an examination through a micro dissection
\end{abstract}

\footnotetext{
* Este trabajo forma parte de los proyectos de investigación "Familias e individuos. Patrones de modernidad y cambio social (siglos XVI-XXI)" (HAR2013-48901-C6-1-R) y "Entornos sociales de cambio. Nuevas solidaridades y ruptura de jerarquías (siglos XVI-XX)” (HAR2017-84226-C6-1-P), financiados por el Ministerio de Economía, Industria y Competitividad.
} 
Miscelánea | Cambio e Historia: necesidades y posibilidades del análisis historiográfico

disección micro. Se propone lo que hemos denominado «experiencias de transformación» como un instrumento para indagar en los procesos de cambio y como un medio para abordar la complejidad de los factores que están en juego. Esto significa estudiar los cambios sociales desde los episodios micro de la vida social, es decir, analizar todos los momentos vividos en relación con ciertas mutaciones sociales en contextos determinados y las formas en que los individuos reaccionan, perciben, gestionan, negocian, promueven o, incluso, se resisten a los cambios. Aunque el trabajo no aborda una cronología específica, gran parte de las reflexiones proceden de los problemas que emergen en el estudio de los siglos XVIII y XIX.

\section{Palabras clave}

cambio social, teoría, metodología, experiencias de transformación, siglo XVIII, siglo XIX. of changes. With this aims, it is proposed what has been called «experiences of transformation» as a way to investigate the processes of change and as a means to address the complexity of the factors that were playing. This means studying social changes through the micro episodes of social life; that is, analyzing all the moments that individuals lived in relation to certain social mutations in specific contexts and the ways in which they reacted, perceived, managed, negotiated, promoted or even resisted changes. Although the work does not address a specific chronology, much of the reflections come from the problems that emerge in the study of the eighteenth and nineteenth centuries.

\section{Key words}

social change, theory, methodology, experiences of transformation, 18th century, 19th century. 


\section{Un debate como introducción}

A lo largo de la década de 1970 se produce un interesante debate a caballo entre la Historia y la Sociología acerca del modo en que debía abordarse el análisis del cambio social. Aunque no ha sido una de las discusiones que más ha trascendido en el campo científico, sí que tuvo elementos que todavía hoy -cincuenta años después- siguen siendo claves para la reflexión y revisión. En 1969, Robert Nisbet publica Social Change and Histoy. Aspects of the Western Theory of Development, una obra en la que intentaba subrayar cómo el pensamiento occidental ha entendido las transformaciones sociales a lo largo de la historia a través de metáforas, especialmente la metáfora del crecimiento de tintes organicistas - metaphor of growth-. La mayor parte del libro es un exhaustivo recorrido por los hitos del pensamiento occidental de dicha metáfora -los griegos, el cristianismo, la Ilustración, la corriente evolucionista del ochocientos y la idea de progreso de ese siglo- y concluye haciendo una crítica a todos esos presupuestos que han distorsionado, según su perspectiva, el estudio del cambio social. En concreto, señalaba seis grandes rasgos: el cambio social no es natural, no es direccional, no se basa esencialmente en factores externos, no es acumulativo, no es fijo ni tampoco es uniforme. Su conjunto de críticas sobre los enfoques del cambio social se puede sintetizar a la perfección en la siguiente cita: «...change proceeding gradually, cumulatively, and irreversibly, through a kind of unfolding of internal potentiality, the whole moving toward some end that is presumably contained in the process from the start. We see none of these in culture: death, degeneration, development, birth» ${ }^{1}$.

En el momento de su publicación, la obra causó un verdadero revuelo y las críticas no se hicieron esperar. En el año 1972 Hubert J. O’Gorman publicaba en la revista History and Theory una revisión de la obra de Nisbet en la que se mostraba especialmente crítico con el privilegio que este autor concedía a los factores internos del cambio social y la estereotipada imagen de los neoevolucionistas ${ }^{2}$. Se trataba de una interesante recensión -algo desenfocada en algunos aspectos- aunque acababa acusando a Nisbet de parafrasear o plagiar intelectual-

1. R.A. Nisbet, Social Change and History: Aspects of the Western Theory of Development, Londres, 1969, 3.

2. H.J. O'Gorman, "Review Work: Social Change and History: Aspects of the Western Theory of Development by Robert A. Nisbet”, History and Theory, 11(1), 1972, 75-89. 
mente a Teggart ${ }^{3}$. O'Gorman se lamentaba de que el autor de Social Change and History fuera incapaz de ver que los eventos históricos y el cambio social se relacionan «esencialmente» como una metáfora. No obstante, la crítica más fuerte, más famosa y más influyente fue la que hizo Gerhard Lenski en 1978 a través del artículo publicado en American Journal of Sociology que fue provocativamente titulado «History and Social Change». La crítica principal a Nisbet ${ }^{4}$ se basó en la imagen que éste dibujaba de los neoevolucionistas; según Lenski, ésta era errónea, simplista y algo caricaturizada: «but the basic point that modern neoevolutionist would make is that we do not have to choose between pure immmanence and pure environmentalism. There is a middle ground $»^{5}$.

Frente a la negación que Nisbet hacía de una verdadera teoría del cambio social, Lenski propoponía lo que denominó como «emergentism», es decir, «the individual cases may be quite unpredictable, quite irregular, but in the aggregate they often display striking regularities ${ }^{6}$. Finalizó su trabajo haciendo gala de la fuerza y la empoderada situación que el neoevolucionismo tenía en esos años y recalcando el heterodoxo progama que había hecho Nisbet: «I seriously doubt that he or other critics of evolutionism can do this without themselves providing us with some new variant of general evolutionary theory-unless they are prepared to ignore the historical record $»^{7}$. El debate no finaliza aquí: en 1979 George Becker hace una contrarréplica a Lenski en la propia revista American Journal of Sociology. Este autor afirmaba con rotundidad que la premisa esencial de Lenski era falsa: «In summary, then, Nisbet's underlying assumption-that the premises of neoevolutionism are grounded in determinism - appears to be fundamentally correct. Contrary to Lenski's assessment, the distinction between general and specific evolution does not make for a more probabilistic evolutionism. The difficulty with Lenski's brand of neoevolutionist position is that, at the primary level of explanation, it remains the evolutionism of the $19^{\text {th }}$ century» ${ }^{8}$.

El punto final de este debate lo podemos situar en el trabajo de Raymond Boudon de 1983, aunque en realidad las réplicas del debate continuaron. Publicado en The British Journal of Sociology bajo el título de «Individual Action and Social Change: A No-Theory of Social Change», Boudon trataba casar las perspectivas de Nisbet y Lenski reconociendo que los sociólogos sí que podían tener un importante papel en el debate del cambio social. Concluía, además, haciendo una llamada de atención y sintetizado perfectamente el di-

3. F.J. Teggart, "The Circumstance or the Substance of History", The American Historical Review, 15, 1919, 709-719; Prolegomena to History: The Relation of History, Literature, Philosophy, and Science, Berkeley, 1916; Theory of History, New Haven, 1925. Hubo una reedición posterior de sus obras: Theory and Porcesses of History, Berkeley y Los Angeles, 1962.

4. No se puede olvidar que Lenski había publicado en 1969 su obra Power and Privilege. A Theory of Social Stratification, y el propio Nisbet hace una sutil crítica al modelo de tipología de sociedades.

5. G. Lenski en "History and Social Change", American Journal of Sociology, 82(3), 1976, 556.

6. Ibídem, 558.

7. Ibídem, 563.

8. G. Becker, "Comment on Lenski's «History and Social Change»", American Journal of Sociology, 84(5), $1979,1241$. 
lema de los estudios de cambio social: «That there are no laws, regularities or trends, but partial, local and temporary, does not indicate that social change is just sound and fury» 9 . Lo cierto es que el debate desarrollado en esta década de 1970 resulta fascinante por muchas razones, especialmente porque la disciplina histórica parecía estar en el corazón de la discusión sobre los cambios sociales, como si fuera la disciplina matriz a partir de la cual se elaboraban los esquemas e interpretaciones esenciales sobre las mutaciones sociales a lo largo del tiempo. Sin embargo, visto desde la incapacidad actual que tiene la historiografía por formular nuevas propuestas metodológicas sobre las transformaciones sociales, se puede afirmar que se trataba de una ilusión. De hecho, Eric J. Hobsbawm puntualizaba en 1971 -momento clave en el que se gestaba el debate Nisbet-Lenski- que «la historia social (...) [no] ofrece, por el momento, modelos o marcos analíticos útiles para el estudio de transformaciones socioeconómicas históricas a largo plazo. La verdad es que, si exceptuamos tendencias como el marxismo, el cuerpo principal no se ha preocupado, ni siquiera se ha interesado, por tales cambios» ${ }^{10}$.

\section{Problemas y necesidades del análisis histórico del cambio social}

Lo cierto es que por aquellos años en los que se desarrolló el mencionado debate la situación era mucho más sombría de lo que parece retratarse. El estructural-funcionalismo, que era aún en los años 1970 una de las corrientes hegemónicas -aunque ya enfrentándose a fuertes y abiertas críticas- apenas se había interesado por el cambio social desde la perspectiva histórica. Una excepción es el trabajo de Neil J. Smelser, quien tituló su obra principal como An Application of Theory to the British Cotton Industry ${ }^{11}$. Por el lado contrario, el marxismo -la otra corriente hegemónica de esos años- sí que había erigido al cambio social como un tema central de investigación, estudiándolo en profundidad y desde multitud de perspectivas ${ }^{12}$. En cualquier caso, este paradigma mostraba importantes problemas en su misma definición y formulación pues se convertía en algo así como una profecía autocumplida -el esquema teórico y las hipótesis acababan por condicionar en extremo los resultados-. No obstante, existen trabajos encuadrados dentro de esta corriente, o al menos cercanos a ella ${ }^{13}$, que son

9. R. Boudon, "Individual Action and Social Change: A No-Theory of Social Change. Hobhouse Memorial Lecture", The British Journal of Sociology, 34(1), 1983, 16.

10. E.J. Hobsbawm, "De la historia social a la historia de la sociedad", Historia Social, 10, 1991 [versión original de 1971], 11.

11. N.J. Smelser, Social Change in the Industrial Revolution, 1770-1840. An Application of Theory to the British Cotton Industry, Illinois, 1959.

12. R.J. Holton, "Marxist Theories of Social Change and the Transition from Feudalism to Capitalism", Theory and Society, 10(6), 1981, 833-867.

13. Excelentes son los ejemplos que han abordado las revoluciones como hito fundamental de los cambios sociales. E.J. Hobsbawm, La era de la revolución, 1789-1848, Buenos Aires, 2009 [traducción de The Age of Revolution: Europe 1789-1848, 1962]; Ch. Hill, A Nation of Change and Novelty: Radical Politics, Religion and Literature in Seventeenth-century England, Londres y Nueva York, 1990. 
todavía fundamentales para entender y plantear el cambio social como problema historiográfico. La obra que mejor representa este hecho es, aunque no desde una perspectiva estrictamente marxista, La gran transformación de Polanyi. En ella los cambios sociales son derivados o consecuencias directas de la emergencia del capitalismo y la economía de mercado -lo que denomina como la emergencia de la «sociedad de mercado»- ${ }^{14}$. Sin embargo, quien merece una mayor atención es E. P. Thompson, quien renovó en profundidad los planteamientos marxistas clásicos a través de una nueva forma historiográfica de observar y analizar las mutaciones sociales: relegó el modelo a un segundo plano, privilegió una investigación más indagatoria que corroborativa y revolucionó el concepto de clase al entenderla como un producto histórico de experiencias y de relaciones, negando así que fuera una estructura o categoría con validez en sí misma ${ }^{15}$.

Fuera de estas dos corrientes mayoritarias, y abordando el desarrollo de los años 1980, 1990 y 2000, la situación no parece mejorar. El desgaste de los dos grandes paradigmas científicos permitió que florecieran multitud de corrientes historiográficas pero muy pocas posaron su mirada en el debate conceptual y metodológico del cambio social. Cabría señalar al respecto a Peter Burke y, concretamente, su obra Historia y teoría social. En la primera edición de 1992 reconoce que el cambio social es un importante problema para los historiadores e historiadoras aunque hace un tratamiento muy vago y ambiguo -se limita a formularlo a través de la exposición del enfoque organicista de Spencer y el dialéctico de Marx-. En la versión de los años 2000, Burke amplía el capítulo respectivo y se pregunta si existe una tercera vía a las ya expuestas. Para ello ofrece algunas ideas de Tocqueville, Giddens, Mann y Tilly, y subraya las investigaciones históricas de Elias, Foucault, Braudel, Le Roy Ladurie, Wachtel y Sahlins. Lamentablemente, y a pesar del interesante repaso historiográfico, no llegar a formular ninguna conclusión vigorosa, lo que demuestra la debilidad y pobreza del cambio social como verdadero objeto historiográfico. Burke se limita a afirmar que «ningún modelo de cambio social satisfará por completo a los historiadores, debido al interés profesional de éstos en la variedad y diferencia» ${ }^{16}$.

La sociología histórica, en cambio, sí que ha mostrado bastante preocupación por el asunto aunque el calor con el que se debatió en los años 1980 y 1990 se ha enfriado en gran medida. Mención aparte merece la obra de Norbert Elias, un verso suelto de su época -comienza su obra en la década de 1930 pero no tuvo relevancia hasta 1970- que se ha con-

14. K. Polanyi, La gran transformación: los orígenes políticos y económicos de nuestro tiempo, México, 2006 [traducción de The Great Transformation, 1944]. Otras investigaciones marxistas que siguen la estela de Polanyi, aunque con obvias diferencias son: J. Merrington, "Town and Country in the Transition to Capitalism", New Left Review, 93(I), 1975, 71-92; E.A. Wrigley, Gentes, ciudades y riqueza: la transformación de la sociedad tradicional, Barcelona, 1992 [traducción de People, Cities, and Wealth. The Transformation of Traditional Society, 1987].

15. E.P. Thompson, La formación de la clase obrera en Inglaterra, 2 vols. Barcelona, 1989 [traducción de The Making of the English Working Class, 1963]. Véase también G.S. Jones, Languages of Class: Studies in English Working Class, 1832-1982, Cambridge, 1983.

16. P. Burke, Historia y teoría social, Buenos Aires, 2008 [traducción de History and Social Theory, 2005], p. 203. 
vertido en uno de los referentes más importantes de la historiografía que se interesa por los cambios en el largo plazo. De una corriente más cultural y cualitativa ${ }^{17}$, escribió $E l$ proceso de civilización y La sociedad cortesana. Además de entender la sociedad como una «configuración» - un tejido de relaciones y dependencias-, es sugerente observar cómo este autor comprende las transformaciones como un doble movimiento de diferenciación-integración y, al mismo tiempo, de especialización-fusión ${ }^{18}$. Por otro lado, la sociología histórica norteamericana -nacida en los años 1970 y consolidada en los 1980 y 1990- ha tenido en el centro de sus intereses los cambios sociales que se produjeron desde el siglo XVI hasta el XX. Destacan al respecto las extensas contribuciones de I. Wallerstein y M. Mann: el primero entiende la historia como la formación del sistema-mundo, en donde el cambio social tiene una casuística siempre externa, derivada de la evolución de la economía-sistema ${ }^{19}$; y el segundo ha creado una historia del poder a través de sus formas - distributivo y colectivo, extensivo e intensivo, autoritario o difuso- y sus tipos — político, militar, económico e ideológico- ${ }^{20}$. Dentro de esta sociología histórica también son reseñables las aportaciones de Charles Tilly, quien intenta explicar la formación del estado-nación a través de las revoluciones y las diferentes combinaciones de coerción-capital ${ }^{21}$, y Theda Skocpol, quien modelizó el cambio social a través de las revoluciones sociales en su famoso ensayo comparativo entre Francia, Rusia y China ${ }^{22}$.

En este punto, cabe volver a Nisbet y preguntarnos si sus inquietudes y sus problemas han sido resueltos por la historiografía actual. Desde nuestro punto de vista, muchos de los puntos esbozados en 1969 siguen todavía vigentes y abiertos; aún hoy es perceptible el recurrente uso de las metáforas del crecimiento o de tipo organicista para analizar y explicar las transformaciones sociales a lo largo de la historia. Unas veces más explícita-

17. En esta corriente también se puede incluir a R. Bendix, Nation-Building and Citizenship: Studies of Our Changing Social Order, Nueva York y Londres, 1964.

18. N. Elias, El proceso de civilización: investigaciones sociogenéticas y psicogenéticas, México, 1989 [traducción de Über den Prozeß der Zivilisation, 1939]; La sociedad cortesana, México, 2012 [traducción de Die höfische Gesellschaft, 1969].

19. I.M. Wallerstein, El moderno sistema mundial I. La agricultura capitalista y los orígenes de la economía mundo europea en el siglo XVI, El moderno sistema mundial II. El mercantilismo y la consolidación de la economía-mundo europea: 1600-1750 y El moderno sistema mundial III. La segunda era de gran expansión de la economía-mundo capitalista, 1730-1850, México, 2010 [traducciones de The Modern World System I, 1974; II, 1980; III, 1989].

20. M. Mann, Las fuentes del poder social I. Una historia del poder desde los comienzos hasta 1760 d.C. y Las fuentes del poder social II. El desarrollo de las clases y estados nacionales, 1760-1914, Madrid, 1991 [traducciones de The Sources of Social Power I, 1986; II, 1993]. Existen otros dos tomos de reciente publicación: The Sources of Social Power III. Global Empires and Revolution, 1890-1945, Cambridge, The Sources of Social Power IV. Globalizations, 1945-2011, Cambridge, 2013.

21. Ch. Tilly, Coerción, capital y los estados europeos, 990-1990, Madrid, 1992 [traducción de Coertion, Capital, and European States, AD 990-1992, 1990]; Las revoluciones europeas, 1492-1992, Barcelona, 2000 [traducción de European Revolutions, 1492-1992, 1993].

22. T. Skocpol, Los Estados y las revoluciones sociales: un análisis comparativo de Francia, Rusia y China, México, 1984 [traducción de States and Social Revolutions, 1979]. 
mente y otras de forma implícita, el recurso de ver los cambios como pasos y transiciones -evidenciado en conceptos, imágenes, inercias investigadoras-, como lo excepcional en una concepción temporal a base de estadios o épocas fácilmente caracterizables -y por tanto estáticas-, sigue vigente. Los siglos XVIII y XIX son un excelente ejemplo de ello puesto que son las centurias que aún se siguen definiendo como de transición -casi irreversible- desde la sociedad tradicional a la moderna, de la sociedad feudal a la de clases, de la sociedad de los linajes a la de los individuos, de la sociedad noble a la burguesa, de la sociedad del nacimiento/adscripción a la del mérito/adquisición, de la sociedad militante a la industrial, de la sociedad mecánica a la orgánica, de la sociedad del patronazgo a la de la burocracia o de una sociedad comunitaria a otra asociativa ${ }^{23}$.

En este trabajo partimos de una idea base: no existió ninguna transición. No hubo un desarrollo lineal entre el punto A y el punto B, como tampoco hubo una evolución entre dos modelos de sociedad, entiendo ésta en un sentido positivista. Durante el setecientos y el ochocientos no se produjo ningún paso entre el punto A -léase sociedad estamental o similar- y el punto B -léase sociedad burguesa o sinónimo- porque, en primer lugar, éstas no existieron como tal, no fueron realidades per se, sino meras categorías utilizadas por los historiadores e historiadoras, con mayor o menor acierto, para describir e intentar caracterizar rígidamente y con simplismo a una realidad social cambiante ${ }^{24}$. No hubo transición, en segundo lugar, porque las transformaciones no son lineales, evolutivas ni acumulativas, no son el resultado necesario de una pugna o tensión entre lo nuevo y lo viejo. Estas categorías -nuevo y viejo- no son fenómenos puros ni fácilmente reconocibles en la vida social; fueron, en verdad, dos caras de una misma realidad que existieron por su relación mutua, se necesitaron recíprocamente porque lo nuevo se define en relación con lo viejo y viceversa. Por tanto, durante los siglos XVIII y XIX no se produjo la irremediable transición de lo nobiliario a lo

23. Algunos de los autores más sobresalientes que han desarrollado estas perspectivas han sido Marx, Spencer, Durkheim, Weber, Tönnies, Parsons y Elias. Cada uno de los análisis de estos autores han generado diferentes tendencias y escuelas interpretativas que han dominado en mayor o menor medida el siglo $\mathrm{XX}$. Junto al materialismo histórico, iniciado entre otros por Marx, y el estructural-funcionalismo, cuyos orígenes pueden situarse en Durkheim, se podría añadir la vertiente weberiana que ha sido, de hecho, la predominante en el último cuarto del siglo XX y principios del XXI. La bibliografía sociológica al respecto es amplísima, tanto en lo referente al enfoque teórico y metodológico como los procesos de transformación social de los siglos XIX, XX y XXI.

24. Theda Skocpol señalaba que en el seno de la sociología histórica es posible discernir una corriente que ella ha llamado «interpretativa». Los autores encuadrados en esta perspectiva tienen en común su interés por el uso de conceptos para «elaborar interpretaciones significativas de grandes procesos históricos». T. Skocpol, "Temas emergentes y estrategias recurrentes en Sociología Histórica", Historia Social, 10, 1991[traducción de "Emerging Agendas and Recurrent Strategies in Historical Sociology", 1984], 115. Dentro de esta corriente Skocpol destaca a R. Bendix, "Concepts and Generalization in Comparative Sociological Studies", American Sociological Review, 28(4), 1963, 532-539; W.H. Dray, Philosophical Analysis and History, Nueva York, 1966. También incluye a: Geertz, Hexter, Johnson, Ragin y Zaret, Rock, Stone, Taylor, Thompson y Wolff. 
burgués -o de lo estamental a lo individual...- porque ni una cosa ni otra fueron realidades dicotómicas e independientes, coherentes y estables.

El principal problema de todo ello es que el cambio social nunca llegó a existir como hecho, como cosa o como un fenómeno único; es más, no es una categoría que pueda ser investigada directamente. Posiblemente sea más adecuado hablar de pequeños episodios de transformación y de micro-acontecimientos de cambio en donde se dieron mutaciones que fueron generalizando diferentes formas de respuesta ante la realidad social existente. La historiografía puede -y debe- reivindicar un concepto mínimo de cambio social, es decir, el que dé cuenta de las transformaciones sociales a través de los pequeños hechos, de los contextos cotidianos y de las micromutaciones de la sociedad. Dicho de otro modo, quizá sea necesario entender el cambio social como un fenómeno de fenómenos, descomponiéndolo en pequeños episodios, y como una realidad relacional que se genera a partir de las diferentes formas de actuar, pensar y reflexionar socialmente ante contextos diferentes ${ }^{25}$.

El concepto básico de cambio social con el que trabajamos viene de la revisión sociológica que se ha producido en los últimos años. Una vez que se han puesto en evidencia los problemas de los modelos organicistas-sistemáticos de la sociedad y del cambio, así como de la dicotomía clásica entre estática y dinámica social, ha emergido una perspectiva que $\mathrm{P}$. Sztompka ha denominado «campo social dinámico». Este autor parte de dos ideas esenciales para reformular el cambio social que nosotros adoptamos: por un lado, es necesario subrayar las «cualidades dinámicas y permeables de la realidad social, esto es, concebir la sociedad en movimiento»; y, por otro lado, evitar ver a la sociedad única o fundamentalmente "como un objeto, esto es, des-reificar la realidad social $»^{26}$. Su concepto de cambio social es co-sustancial a su definición de realidad social, esto es, algo relacional y dinámico. La sociedad, según Sztompka, es una «realidad inter-individual», «es lo que existe entre, o en medio de, individuos humanos; una red de conexiones, lazos, dependencias, intercambios, lealtades», o dicho de otro modo, «un tejido social específico o un entramado social que engarza y agrupa a la gente ${ }^{27}$. La sociedad es en sí misma cambio social porque «toda realidad social es pura dinámica, un flujo de cambios de velocidades, intensidades, ritmos y tiempos diversos». No obstante, la aportación más relevante de este autor es su apuesta por evitar una visión lineal de las transformaciones y desechar cualquier connotación de evolución, desarrollo o progreso. En resumen, cambio social es una forma de entender cómo el «campo [social] inter-individual» está «constantemente en movimiento; se expande y se contrae (...); se fortalece y se debilita (...); une y desintegra (...); se entremezcla o separa de otros segmentos del campo» ${ }^{28}$.

25. Respecto al término relacional, participamos de lo expuesto en Pierpaolo Donati, "Pensamiento sociológico y cambio social: hacia una teoría relacional”, Revista Española de Investigaciones Sociológicas, 63, 1993, 29-51.

26. P. Sztompka, Sociología del cambio social, Madrid, Alianza, 2008 [traducción de The Sociology of Social Change, 1995], 31.

27. Ibídem, 32.

28. Ibídem. 
Véase como ejemplo de ello que el cambio social de los siglos XVIII y XIX, o lo que generalmente se ha interpretado como la transición de la sociedad noble a la burguesa -o las diferentes denominaciones que ha recibido-, debe aminorar la fuerte carga determinista que todavía suele llevar implícita ${ }^{29}$. Posiblemente sea más adecuado hablar de cambio social - sin el artículo determinado- o, incluso mejor, de «transformaciones sociales», una expresión que recupera, en cierto modo, el valor de la contingencia como una variable fundamental en el análisis histórico y, muy especialmente, en el examen de mutaciones sociales $^{30}$. Sea cual sea el término que se utilice, es importante recalcar que no encierra en sí mismo un significado concreto, específico o rígido; al contrario, es un concepto de conceptos, que recoge una multitud de procesos de naturaleza diferente -aunque fuertemente relacionados entre sí- que no tienen por qué desarrollarse al compás, a la misma velocidad, ni tampoco tienen un orden predeterminado ${ }^{31}$.

Para precisar cuáles son los retos que el método histórico tiene frente a las transformaciones sociales, es necesario articular una definición de cambio social y para ello proponemos tres niveles de estudio. El primero, aunque no necesariamente tiene por qué ser el inicial, se conformaría por las transformaciones en las acciones, interacciones, vínculos y estructuras que conforman la sociedad. Se trata del conjunto de mutaciones que se dan en los modos de organización social, de las alteraciones de los patrones en que los individuos actúan y constituyen cadenas de interdependencias, o redes de relaciones, y los cambios en las diversas formas de jerarquización. Dicho en otras palabras, este primer nivel analiza el vasto conjunto de elementos y hechos que conforman la praxis social. Por otro lado, un segundo nivel se centraría en el discurso y el modelo social, concretamente en las modificaciones de los principios y de los valores sociales que dispone teóricamente una sociedad y de los argumentos en que se legitima. Este segundo nivel sería, resumidamente, el que estudia los cambios en la ideología social ${ }^{32}$-entendiendo ideología como conjunto de ideas fundamentales-.

A estos dos niveles cabría sumar otro más complejo que en realidad cohesiona y da sentido a los precedentes. Sería el que examina las variaciones en las formas y los modos en que una sociedad se piensa a sí misma, se representa y se analiza como algo diferente, es decir, sería un meta-nivel o el nivel de reflexión social del cambio. No obstante, el problema principal que plantea este nivel es que es necesario, en primer lugar, tener constancia de que existe sociedad como tal, entendida ésta como una entidad autónoma y objetiva -significa-

29. Algunas de estas ideas ya fueron expuestas con claridad en la sociología a mitad del siglo XX, W.E. Moore, Social Change, Englewood Cliffs, Prentice-Hall, 1963.

30. Algunas ideas importantes al respecto en R. Koselleck, Los estratos del tiempo: estudios sobre la historia, Barcelona, 2001; Futuro pasado: por una semántica de los tiempos históricos, Barcelona, 1993 [traducción de Vergangene Zukunft, 1979]. Véase también J. Rüsen, "Cambio social y revolución historiográfica: un enfoque teórico", en I. Olábarri Gortázar, V. Vázquez de Prada y F. J. Caspistegui (Coords.), Para comprender el cambio social: enfoques teóricos y perspectivas historiográficas, Pamplona, 1997, 115-132.

31. Una de las obras sociológicas más reciente, que recoge precisamente este significado de cambio social, es J. McLeod y R. Thomson, Researching Social Change, Londres, 2009.

32. N. Fairclough, Discourse and Social Change, Cambridge, 1992. 
do moderno-, y no meramente como un sumando de individuos y relaciones ${ }^{33}$. Se requiere constatar que una colectividad humana adopta la categoría de cosa, con agencia propia, y eso no se produjo en las sociedades europeas hasta el siglo XVIII y el desarrollo de la opinión pública $^{34}$. Como ha señalado Baker, «the Enlightenment invented society as the symbolic representation of collective human existence and instituted it as the essential domain of human practice ${ }^{35}$, lo cual significa que a partir de la segunda mitad del siglo XVIII la sociedad existirá en su acepción moderna, como un actor social más -el actor social colectivo por antonomasia- que actuará también como referente y como juez del juego social al apoyarse en la cada vez más fortalecida opinión pública ${ }^{36}$. En cualquier caso, el análisis historiográfico de este nivel se centra en las formas en que esa sociedad se piensa, se ve, se imagina y se representa a sí misma como algo diferente y distinto ${ }^{37}$.

Se debe tener presente en todo momento que estos tres niveles se encuentran fuertemente relacionados; son, en verdad, tres caras de una misma realidad. Por ejemplo, si observamos a los sujetos como actores sociales, veremos que son los hombres y las mujeres quienes crean en

33. Algunas precisiones de gran valor se encuentran en M.A. Cabrera y A. Santana Acuña, "De la historia social a la historia de lo social", Ayer, 62(2), 2006, 165-192.

34. Esta afirmación contiene un amplio y profundo debate que es imposible abordar aquí. Para que se produzca la "cosificación" de la sociedad debe ser un proceso socializado y generalizado en la propia sociedad. Eso, sin lugar a dudas, presenta amplias dificultades sin la existencia de la opinión pública. Con anterioridad pudo existir la idea de sociedad, especialmente en grupos de intelectuales, pensadores y tratadistas, pero durante la Edad Moderna es difícil hablar de una sociedad que se ve y se entiende a sí misma como tal. Por eso el concepto de orden social sería mucho más adecuado. M.B. Becker, The Emergence of Civil Society in the Eighteenth Century: A Privileged Moment in History of England, Scotland, and France, Bloomington y Indianapolis, 1994, 5 y siguientes. Algunas ideas al respecto, I. Mazzola, "Comunidad, sociedad: reflexiones desde la historia conceptual", Nómadas, 29, 2011, 221-244.

35. K.M. Baker, "Enlightenment and the Institution of Society: Notes for a Conceptual History", in W. Melching y W. Velema (Eds.), Main Trends in Cultural History: Ten Essays, Amsterdam-Atlanta, 1994, 84. Véase también R. Koselleck, Critique and Crisis. Enlightenment and the Pathogenesis of Modern Society, Oxford y Munich, 1988 [traducción de Kritik und Krise, 1973]; A.J. La Vopa, "Conceiving a Public: Ideas and Society in Eighteenth-Century Europe”, Journal of Modern History, 64(1), 1992, 79-116.

36. J. Habermas, Historia y crítica de la opinión pública: la transformación estructural de la vida pública, Barcelona, 1981 [traducción de The Structural Transformation of the Public Sphere, 1962]. Después de esta obra son múltiples los trabajos que abordan esta cuestión. Por citar dos, relevantes a la temática concreta que abordamos, L. Kaufmann, "Entre la ficción y realidad. La opinión pública en la Francia del siglo XVIII", Historia Contemporánea, n 27, 2003, 581-600 y V. Cases, "En nacimiento de la opinión pública: problemas, debates, perspectivas", Res Publica, 21, 2009, 149-156.

37. La evolución del concepto en los diccionarios de la Real Academia es significativa. Desde la primera edición del año 1739 hasta la de 1843 el término «sociedad» significaba «compañía de racionales». Desde 1852 la acepción principal paso a ser «reunión mayor o menor de personas, familias, pueblos y naciones». No obstante, no fue hasta 1914 cuando el diccionario recoge verdaderamente el sentido moderno del término: «agrupación natural o pactada de individuos de la especie humana que constituye una unidad distinta de cada uno de los que la forma, con el fin de cumplir, mediante la mutua cooperación, todos o algunos de los fines de la vida.» 
la praxis social la estructura social y, al mismo tiempo, se encuentran condicionados por ella ${ }^{38}$. También son los individuos los portadores y generadores de valores sociales, los cuales existen siempre y cuando esos sujetos los aplican, negocian y reformulan. Finalmente, los individuos, como seres reflexivos de su existencia y de su condición social, pueden mostrar en pequeños hechos de la vida cotidiana cómo la propia sociedad se imagina y se piensa a sí misma ${ }^{39}$.

\section{Hacia una definición de las «experiencias de transformación»}

A pesar de haber propuesto estos tres niveles de estudio del cambio social, cabe preguntarse qué son las transformaciones sociales. La cuestión resulta de enorme dificultad porque partimos de la idea de que el cambio social nunca llegó a existir como hecho, como cosa o como un fenómeno único; por eso, es posible afirmar que el estudio histórico requiere de un giro relacional en el que prevalezca no solo las relaciones sociales como un objeto fundamental de estudio sino también una perspectiva relacional. Esto último significa, en palabras de P. Donati, que los fenómenos sociales «existen "en relación con"; es decir, subraya que el carácter «relativo» de un fenómeno social indica una relación - con su propia estructura, funciones $\mathrm{y}$ articulaciones»-. Su interés fundamental radica en que se puede abogar por un estudio que vaya más allá de un sistema dualista y dicotómico donde las cosas no se definan por la negación del otro. Además, permite superar otras teorías, como por ejemplo la de Giddens, evitando así la constricción de las relaciones sociales en la lógica de «estructuración» en la que la acción genera estructura y la estructura genera acción ${ }^{40}$.

El enfoque sociológico denominado «morfogenético» tiene grandes similitudes con esta aproximación, pues entiende cambio social como «a dialectical relation between human agency and the contexts in which those agents find themselves, contexts that include culture, structure, and physical things. Within that overriding framework, however, change may take a variety of forms $»^{41}$; o, dicho en otras palabras, las transformaciones «emerge out of struggle, struggles between actors situated in social positions with differing power and resources». La

38. Aquí se formula el debate clásico que ha dominado las ciencias sociales a lo largo del siglo XX -acción versus estructura-. Véase el marco historiográfico M.A. García Sánchez, "Sujeto y acción en la sociedad y en la historia”, Espacio, Tiempo y Forma, Serie IV-Historia Moderna, 18-19, 2005-2006, 13-34.

39. En la práctica investigadora eso se constata, tal y como señalaban Ginzburg y Poni, en que los individuos, aunque aparecen en las fuentes en contextos diferentes, mostrando diversas y múltiples dimensiones de sus acciones, de sus experiencias, de sus roles y de sus identidades, siguen constituyendo un mismo ser. C. Ginzburg y C. Poni, "El nombre y el cómo: intercambio desigual y mercado historiográfico", Historia Social, 10, 1993 [traducción de "Il nome e il come", 1979], 63-70.

40. A. Giddens, La constitución de la sociedad. Bases para la teoría de la estructuración, Buenos Aires, 1995 [traducción de The Constitution of Society, 1984]. Dos interesantes aplicaciones del enfoque giddensiano son: Ch. Lloyd, "The Methodologies of Social History: A Critical Survey and Defense of Structurism", History and Theory, 30(2), 1991, 180-219; Explanation in Social History, Oxford y Nueva York, 1986; y P. Abrams, "History, Sociology, Historical Sociology", Past \& Present, 87, 1980, 3-16.

41. D.V. Porpora, "Morphogenesis and Social Change", en Margaret S. Archer (ed.), Social Morphogenesis, Londres, Springer, 2013, 29. 
importancia que esta corriente concede al contexto, al entenderlo como un espacio social y temporal en donde se generan las acciones y experiencias, debe ir parejo al estudio de las relaciones sociales que se crean. En definitiva, para comprender las transformaciones sociales es necesario entenderlas como realidades emergentes en relación con contextos y entornos específicos subrayando «el carácter relacional de la realidad social, como una realidad sui generis «hecha» de relaciones»; $y$, sobre esa premisa, se puede afirmar que el cambio social se produciría «cuando las relaciones propias y específicas de una entidad social se forman con cualidades distintivas que difieren de las precedentes ${ }^{42}$.

Aquí es sugerente introducir nuestra propuesta de «experiencias de transformación», las cuales deben entenderse, ante todo, como microfibras, como esos pequeños hilos que lenta y minúsculamente fueron entretejiendo los cambios sociales. Una primera definición de estas «experiencias» podría ser todos los momentos vividos en relación con ciertas mutaciones sociales en contextos determinados y las formas en que los individuos reaccionan, perciben, gestionan, negocian, promueven o, incluso, se resisten a los cambios. Las «experiencias de transformación» constituirían el medio para estudiar los cambios sociales desde su mínima expresión, desde la cotidianeidad social de los actores individuales o colectivos, puesto que son los productos de la vida social resultantes de las acciones e interacciones, ya sean conscientes o inconscientes, que diversos individuos acometen en determinados contextos y espacios sociales a lo largo del tiempo -la (re)construcción constante de experiencias, acciones/interacciones y contextos/espacios social es relacional, se retroalimenta-. En la categoría de experiencia el tiempo tiene un papel central, lo cual la convierte en una herramienta muy sugerente para analizar la relación pasado-presente-futuro en diacronía, en un continuo temporal. Además, solo a través de las «experiencias» podremos introducir cuatro elementos esenciales: la contingencia como una variable de estudio del cambio social, aunque ésta está mediada por los límites que imponen unos contextos determinados; unir la dimensión racional y consciente de todo ser humano con la inconsciente de forma continua; ver no solo acciones individuales, sino también vivencias colectivas; articular lo abstracto y lejano con lo concreto y cercano; $y$, finalmente, observar la reflexividad de la sociedad a través de pequeños episodios.

El término «experiencia» parece verdaderamente sugerente porque, como señala Koselleck, permite «tematizar el tiempo histórico por entrecruzar pasado y futuro» y, sobre todo, porque posibilita «descubrir el tiempo histórico también en el campo de la investigación empírica ${ }^{43}$. La hipótesis de este autor es que durante el siglo XVIII se produjo el nacimiento de la modernidad y la consumación de un profundo cambio social debido a la separación entre lo que denomina «espacio de experiencia» $\mathrm{y}$ «horizonte de expectativas». En cualquier caso, y a pesar de que esta propuesta ha tenido mucha contestación y varias reelaboraciones ${ }^{44}$,

42. P. Donati, "Pensamiento sociológico y cambio social: hacia una teoría relacional”, Revista Española de Investigaciones Sociológicas, 63, 1993, 29-51.

43. R. Koselleck, Futuro pasado..., op. cit., 337.

44. M. Pikering, "Experience as Horizon: Koselleck, Expectation and Historical Time”, Cultural Studies, 18(2-3), 2004, 271-289; S. Chignola, “Temporizar la historia. Sobre la Historik de Reinhart Koselleck”, 
la categoría «experiencia» es la que resulta más interesante para nuestros objetivos y puede entenderse como:

...un pasado presente, cuyos acontecimientos han sido incorporados y pueden ser recordados. En la experiencia se fusionan tanto la elaboración racional como los modos inconscientes de comportamiento que no deben, o no deberían ya, estar presente en el saber. Además, en la propia experiencia de cada uno, trasmitida por generaciones o instituciones, siempre está contenida y conservada una experiencia ajena ${ }^{45}$.

Fue también E.P. Thompson quien situó el término experiencia como un instrumento central para el análisis de las transformaciones sociales, aunque su aplicación demostró que el concepto «no debería ser entendido como una categoría propositiva sino más bien como la constatación de una limitación. Es una forma de reconocer nuestra forma esencialmente confusa y no estructurada de realizar inferencias sobre la acción humana a partir de los datos empíricos de los que disponemos» ${ }^{46}$. A pesar de los extensos debates sobre la acepción thompsoniana del término, es posible afirmar que su atracción «reside precisamente en su presentación de los acontecimientos a través del punto de vista de los sujetos que los vivencian ${ }^{47} y$, como señaló el propio Thompson, «la "experiencia" (...) es indispensable para el historiador [e historiadora], ya que incluye la respuesta mental y emocional, ya sea de un individuo o de un grupo social, a una pluralidad de acontecimientos relacionados entre sí o a muchas repeticiones del mismo tipo de acontecimiento ${ }^{48}$. Tal y como ha matizado recientemente Martin Jay, los problemas epistemológicos que ha tenido el término experiencia se derivan, por un lado, de las limitaciones dadas por el lenguaje y las variables culturales y, por otro lado, de su doble acepción como vivencia de lo cotidiano y como proceso de aprendizaje $^{49}$. Este autor aboga por una integración de significados y añade que para entender y estudiar verdaderamente las experiencias deben entenderse como un producto de las transformaciones y de los fenómenos de cambio:

Así, la experiencia es punto de intersección entre el lenguaje público y la subjetividad privada, entre los rasgos comunes expresables y la interioridad individual. También se encuentra inscripta entre el sí mismo y el otro, la actividad y la pasividad, etc. Esto se vincula, enfatiza el autor [Martin Jay], con que la experiencia debe implicar necesariamente una relación de diferencia o

Isegoría, 37, 2007, 11-33.

45. R. Koselleck, Futuro pasado... op. cit., 338.

46. C. Rendueles, "Teoría social y experiencia histórica. La polémica entre E.P. Thompson y Louis Althusser", Sociología Histórica, 3, 2013, 193. Véase también H. Sorgentini, "La recuperación de la experiencia histórica: un comentario sobre E.P. Thompson", Sociohistórica, 7, 2000, 53-80.

47. D. López, "La prueba de la experiencia. Reflexiones en torno al uso del concepto de experiencia en la historiografía reciente", Prismas, 16, 2012, 40.

48. E.P. Thompson, Miseria de la teoría, Barcelona, 1978, 19, citado en D. López, "La prueba de la experiencia...", op.cit., 40.

49. M. Jay, Cantos de experiencia. Variaciones modernas sobre un tema universal, Buenos Aires, 2009. 
encuentro con la otredad; es preciso por tanto que suceda algo nuevo, que algo cambie, para que el término sea significativo ${ }^{50}$.

Las «experiencias de transformación» son ese conjunto de vivencias, ya sean acciones, interacciones, reflexiones u omisiones -conscientes, semiconscientes o inconscientes- que nacen y se desarrollan en relación con las transformaciones sociales que se dan en contextos determinados, es decir, las formas de percibir -advertir, interpretar-, asimilar -negociar, gestionar- y procesar - promover, resistir- ciertas mutaciones sociales en acontecimientos y eventos concretos. No obstante, estas experiencias no encierran significados ni interpretaciones unívocas pues, al contrario, serán respuestas un tanto confusas a entornos que están en procesos de mutación.

Un problema que puede surgir al plantear las «experiencias de transformación» es la confusión de los dos primeros niveles de estudio del cambio social, el de la praxis social y la ideología social. Eso genera que multitud de análisis tengan un fuerte sesgo apriorístico y predeterminado al forzar la naturaleza de las evidencias de las acciones y de los comportamientos para que coincidan o se aproximen a los vectores marcados por el discurso. Si bien es cierto que ambos niveles se constituyen y se generan mutuamente, en la investigación histórica del cambio social no se puede suponer a priori la prevalencia de uno sobre el otro ${ }^{51} \mathrm{ni}$ tampoco anticipar que sus transformaciones vayan al unísono. Al contrario, se convertirá en prioritario el análisis de cómo ambos niveles se (re)generan constantemente a través de las citadas experiencias y de cómo acciones, estructuras y discursos son negociados y representados según un contexto y una situación determinada. Para ello, es necesario fomentar un estudio histórico del cambio social que acentúe su carácter indagatorio, explorador y averiguador o, si se quiere, un enfoque más «abierto» ${ }^{52}$, desplazando parcialmente la óptica que prima la contrastación o corroboración de un modelo predeterminado. De hecho, este era uno de los aspectos de Hobsbawm citaba en 1971 como esenciales en la agenda historiográfica:

...intentemos hacer explícitos los presupuestos implícitos con los que operamos, y preguntarnos si este plan es, de hecho, el más idóneo para formular la naturaleza y la estructura de las sociedades y los mecanismos de sus transformaciones históricas (así como los de su estabilidad), o si otros con premisas diferentes pueden hacerse compatibles con él, incluso deben ser preferidos, o sencillamente sobrepuestos para conseguir el equivalente histórico a los retratos de Picasso, que se nos muestran, al mismo tiempo, de frente y de perfil ${ }^{53}$.

50. D. López, "La prueba de la experiencia...", op. cit., 49.

51. Algunas ideas importantes sobre las diferencias entre lo ideal y lo material, o lo simbólico y lo imaginario, en M. Godelier, Lo ideal y lo material. Pensamientos, economías, sociedades, Madrid, 1990 [traducción de L'idéel et le matériel, 1984].

52. P. D. Dwyer y M. Minnegal, "Theorizing Social Change", The Journal of the Royal Anthropological Institute, 16(3), 2010, 629-645.

53. E. J. Hobsbawm, "De la historia social..." op. cit., 16. 
Las herramientas conceptuales que la historiografía despliega para el análisis adquieren en este enfoque del cambio social un protagonismo más que sobresaliente. Resulta esencial la diferencia que Simona Cerutti hace entre lo emic, o las categorías y conceptos que usaron los propios actores que se estudian, y lo etic, o las categorías creadas por el investigador ${ }^{54}$. Esta autora aboga por desplegar un estudio en el que se privilegie «el lenguaje y la lógica» de los mismos individuos que se examinan, sumergiéndose en sus cosmovisiones, permitiendo de este modo constituir una interesante y acertada base estratégica para el examen y, también, la comprensión de los cambios sociales ${ }^{55}$. Muy parecida es la propuesta de Peter Burke, quien aboga por convertir a las identidades sociales en un objeto central de la historiografía aunque «in order to reconstruct these identities, historians need to make a carefully study of what is sometimes called the 'social vocabulary' of a given society» ${ }^{56}$. Añade, además, que ese «social vocabulary» no son piezas objetivas con las que se puede (re)construir y (re)ensamblar la jerarquía social, sino que «this hierarchy looks very different according the one's place in it $»^{57}$. Esta propuesta comparte muchos elementos con la (re)formulación que Sewell hace de «lo social», entendiendo esto como «una red articulada y cambiante de prácticas semióticas que construye y transforma los marcos materiales que establecen las matrices de esas prácticas [sociales] y que delimita sus consecuencias» - es decir, un entorno construido ${ }^{58}$ - . Por tanto, uno de los ejes sobre los que se debe asentar el análisis del cambio social a través de las «experiencias de transformación» es su naturaleza emic, es decir, a través de la «reconstrucción de los códigos semióticos» de las realizaciones humanas y, además, abarcar «los entornos construidos que son el efecto de esas realizaciones» ${ }^{59}$.

es importante (...) reconstruir percepciones, experiencias, los discursos y los hechos, pues tienen conciencia de que las percepciones, las experiencias, los discursos y los hechos tiene condiciones y consecuencias no necesariamente presentes en la mente de quienes perciben,

54. S. Cerutti, "Microhistory: Social Relations versus Cultural Models? Some Reflections on Stereotypes and Historical Practices", en A.M. Castrén, M. Lonkila y M. Peltonen (eds.), Between Sociology and History. Essays on Microhistory, Helsinki, 2004, 17-40. Sobre las implicaciones de conceptos y cambio social véase cómo Koselleck señala que "para el ámbito de la lengua alemana, se puede mostrar que desde 1770, aproximadamente, surgieron una gran cantidad de nuevos significados de palabras antiguas y neologismos que modificaron (...) todo el ámbito social y político de la experiencia y fijaron un nuevo horizonte», $\mathrm{R}$. Koselleck, Futuro pasado... op. cit., 116.

55. El debate emic y etic se fundamenta en K. L. Pike, Language in Relation to a Unified Theory of Structure of Human Behavoir, Mouton, 1967 y M. Harris, "History and Significance of the Emic/Etic Distinction", Annual Review of Anthropology, 5, 1976, 329-350.

56. P. Burke, "The Language of Orders in Early Modern Europe", M.L. Bush (ed.), Social Orders and Social Classes in Europe since 1500: Studies in Social Stratification, Londres, 1992, 10.

57. Ibídem, p. 11.

58. W. H. Sewell, "Por una reformulación de lo social”, Ayer, 62(2), 2006, 71.

59. Ibídem, pp. 71-72. 
experimentan, se comunican y actúan, de lo que se deduce la necesidad de analizar las múltiples interconexiones entre estructuras y procesos por una parte, y percepciones, experiencias, construcción de significados y voluntad de actuar por otra ${ }^{60}$.

\section{Más allá de las experiencias: los cambios a través de siluetas}

Nuestro objetivo principal es comprender cómo los individuos fueron recreando continuamente, a través de sus experiencias vitales, el desconcertante camino que hubo -y hay- entre el ayer y el hoy. Apostamos, por tanto, por un análisis del cambio social eminentemente abierto e indagatorio que diseccione microscópica y cualitativamente a través de las experiencias unas transformaciones nacidas en diferentes procesos de diversa naturaleza. Abogamos por el estudio de cómo se produjeron esos cambios en los pequeños episodios y engranajes de la vida social. El verdadero objeto de esta operación no será otro que el complejo mundo de las experiencias, un análisis del cambio social a través de un cuidadoso periplo por las forman en que esas mutaciones fueron vividas y experimentadas en la cotidianeidad social, lo cual viene a incidir en algo que el propio Robert Nisbet subrayó y consideró como vertebral:

History in any substantive sense is plural. It is diverse, multiple, and particular. There have been innumerable histories since the first history of the first human group began (...). Such plurality is, however, but a part of the problem, though admittedly the major part (...). Many histories, many areas, many times! The mind boggles at the task of encapsulating such diversity within any empirically drawn formula or synthesis. It cannot be done; not empirically, not pragmatically ${ }^{61}$.

Ahora bien, esta pluralidad y diversidad de la realidad histórica, aunque cierta y esencial en el enfoque del estudio, plantea serios problema. Se puede correr el riesgo de quedar atrapado por la particularidad de esas infinitas vivencias que un historiador o historiadora puede llegar a analizar. El propio Nisbet era consciente del problema e intentó esbozar una solución que, pese a ser interesante, era bastante vaga en su formulación: «on the evidence of history, however, such changes are small and frequently cancel themselves out in the course of time. The important point, in any event, is that of making the distinction between such changes and change of larger, structural significance» ${ }^{62}$. Si aplicamos la idea de Nisbet a las «experiencias de transformación», habría que diferenciar entre aquellas que crean un precedente y desencadenan cambios de mayor calado -crean un verdadero punto de inflexión, se repiten o son compartidas por un grupo de individuos- y las que no trascienden de su contexto o entorno.

Se iría dibujando, de este modo, un complejo y abigarrado mapa de experiencias que difícilmente puede ser encorsetado por una modelización -la cual sesga, a la postre, esa mis-

60. J. Kocka, "Historia social, un concepto relacional”, Historia Social, 60, 2008, 162.

61. R. Nisbet, Social Change and History... op. cit., 240-241.

62. Ibídem, 278.

Revista de historiografía 29, 2018, pp. 277-296 
ma realidad en cambio-. En este punto, es muy recurrente el concepto de «eventful temporality» que William $\mathrm{H}$. Sewell propone tras hacer una profunda crítica al análisis de la temporalidad en las Ciencias Sociales y en Historia. Este término podría entenderse como «the eventful conception of temporality, (...) assumes that social relations are characterized by path dependency, temporality hetegeneous causalities, and global contingency» ${ }^{63} \mathrm{y}$ en su formulación más acabada y completa se refiere a:

Eventful temporality recognizes the power of events in history. Social life may be conceptualized as being composed of countless happenings or encounters in which persons and a group of persons engage in social action. Their actions are constrained and enabled by the constitutive structures of their societies. Most happenings (...) reproduce social and cultural structures without significant changes (...). Events may be defined as that relatively rare subclass of happenings that significantly transforms structures. An eventful conception of temporality, therefore, is one that takes into account the transformation of structures by event ${ }^{64}$.

La imagen que ofrece Sewell es sumamente interesante: un mundo social lleno de eventos e interacciones que, al mismo tiempo, está reproduciendo y cambiando las estructuras. Se evoca, de este modo, una imagen algo confusa y enmarañada -las vivencias están, al mismo tiempo, construyendo y erosionando continuamente el orden social- pero muy sugerente si se desea comprender las transformaciones sociales a través de su diversidad. En la intersección que se da entre las persistencias y las mutaciones de los eventos e interacciones emerge la clave para salir de la abrumadora inmensidad -y circularidad- de las experiencias de transformación. Este mapa abigarrado y dinámico de experiencias debe estar, en primer lugar, desprovisto de un sentido previo y de una intencionalidad dada -evitando cualquier recurso a metáforas lineales o direccionales- y, en segundo lugar, debería enfatizar y subrayar precisamente los diferentes ritmos que tuvieron las transformaciones, las varias direcciones que adoptaron, los movimientos oscilantes que adquirieron e, incluso, las formas desconcertantes y contradictorias que mostraron.

Reconociendo que el cambio social es real, aunque no una realidad en sí misma, es necesario subrayar su carácter eminentemente polimórfico: no adopta una única forma o representación y depende del enfoque o lente que se utilice. Si se trasciende del nivel básico que aborda las experiencias y abrimos el campo de visión, nos encontraremos ante un mundo social tremendamente complejo, confuso y abrumador, en el que podrán advertirse formas o «siluetas» de cambio que no son siempre unívocas. Póngase como ilustración una pintura, la obra titulada Summertime: Number $9^{a}$ de Jackson Pollock -1948-. Será indudable que cada observador verá una realidad distinta, una combinación única de color, perspectiva, formas e intencionalidad, aunque habrá unanimidad en el movimiento dominante que late en la obra, en el flujo de fuerzas que se transmite ante unas siluetas negras que dominan la composición $\mathrm{y}$, al mismo tiempo, se integran plenamente en el conjunto y el todo. El término de «silueta»,

63. W. H. Sewell, Logics of History. Social Theory and Social Transformation, Chicago y Londres, 2005, 102. 64. Ibídem, 100. 
aplicado a las transformaciones sociales, hace referencia directa a los cambios y debe entenderse, tal y como expresan sus acepciones, como el dibujo sacado en un contorno de sombras o a la forma que presenta un objeto sobre un fondo. Dicho en otras palabras, los bocetos de las mutaciones que se van apuntando a partir de las experiencias.

Esto significa que la historiografía no tiene por qué investigar un perfil o una forma concreta, limpia y clara de las transformaciones sociales. A nuestro entender, hacer un dibujo nítido de los cambios provocaría reducir y minimizar su complejidad, que es uno de los elementos fundamentales y constitutivos de las mutaciones sociales. Por eso, se podría incluso afirmar que el resultado de las investigaciones sería un retrato impresionista de los cambios. Las transformaciones sociales son multimórficas y cambian según dónde y cómo se miren; se componen de pequeñas pinceladas que van conformando contornos un tanto equívocos y constituyendo retratos un tanto nebulosos. Es por ello que nos interesa observar las siluetas que van adoptando y cómo, a su vez, se van insinuando a lo largo del tiempo. El punto de partida y de llegada puede ser el mismo: el cambio social como un fenómeno histórico compuesto de fibras finísimas, delicadas y muy complejas, que se iban entretejiendo poco a poco, cuando no se deshilaban, formando una realidad que siempre fue incierta. La visión del cambio social desde la Historia no debe ser lineal, no tiene por qué ser un proceso necesariamente evolutivo ni estrictamente progresivo, sino una realidad compleja, de varias direcciones y velocidades, que siempre estuvo sujeta a la contingencia del devenir y al desconcierto de sus contemporáneos.

Esta es la idea principal que Antonio Flores expone magistralmente en su obra Ayer, hoy y mañana; o la fe, el vapor y la electricidad. Cuadros sociales de 1800, 1850 y 1899. En el año 1863 este autor, encuadrado en la corriente costumbrista, publicaba el primer tomo de la mencionada obra haciendo un sugerente retrato de la España en la que vivía, en la que había vivido y en la que - creía que- viviría. Subrayaba enormemente que la sociedad estaba dominada por el cambio, por las diferencias entre un pasado y un presente totalmente diferentes. Al recordar los tiempos del Ayer, o la sociedad de la fe de 1800, decía: «Dichosa edad y felices tiempos aquellos en que el hombre venia al mundo con la precisa obligación de creerlo todo, vivía sin dudar de nada y moría en la seguridad de que cuanto le había rodeado y cuánto le había prometido, era la pura verdad!» ${ }^{65}$. Tras esta melancólica y compasiva mirada, no cabe duda de que el universo de Antonio Flores se había transformado excepcionalmente en un tiempo relativamente corto. El cambio que se había producido no era baladí ni secundario: el viejo orden había caído e iba lentamente difuminándose mientras que emergía un mundo nuevo caracterizado por unas brumosas características. Lo que resulta más interesante de la obra de Antonio Flores es la perspectiva que utiliza: una óptica que permite ver y analizar el pasado, el presente y las transformaciones a través de las experiencias:

Cierra los ojos, recoge el aliento, muérdete la lengua y déjame que, atado de pies y de manos, te lleve Hoy al cementerio de los de ayer, para que cuando llegue MAÑANA lo veas sin asombro

65. A. Flores Ayer, hoy y mañana, o la fé, el vapor y la electricidad. Cuadros sociales de 1800, 1850 y 1889 , Madrid, 1863, I, Xv. 
Miscelánea | Cambio e Historia: necesidades y posibilidades del análisis historiográfico

convertido en un almacén de memorias. Si entonces te dicen que aquella edad pertenece a los tiempos fabulosos y que aquellos hombres son otras tantas figuras mitológicas, podrás decir que no es cierto, y que, gracias a esta obra que me ves escribir al borde de sus sepulcros y cuando aún humean sus cenizas, lo has visto, lo has oído hablar y casi has tratado con ellos. No temas andar a ciegas por las regiones de lo pasado, ni hacer el mudo entre aquellas gentes, pues cuanta mayor sea la oscuridad y más profundo el silencio, mejor comprenderás la situación. Yo cuidaré de avisarte para que te arranques la venda de los ojos y sueltes la lengua cuando haya algo que merezca verse y puedas hablar sin que te recojan las palabras (...) Escusado me parece encargarte, y aun así todo no quiero excusarme de hacerlo, que no traigas contigo cerillas fosfóricas ni cosa alguna que pueda alumbrarnos en el camino que vamos a andar, porque las luces serían decomisadas y volveríamos a quedar a oscuras. Preferible es por lo tanto conservar la oscuridad tal cual la encontramos, y respetando el silencio de los sepulcros que vamos a visitar, abrazar en globo y de una sola ojeada la generación que duerme entre ellos ${ }^{66}$.

66. Ibídem, xvii-xviii. 